\title{
Effects of Titratable Acidity and Organic Acids on Enamel Erosion In Vitro
}

\author{
Eun-Jeong Kim and Bo-Hyoung $\mathrm{Jin}^{\dagger}$ \\ Department of Preventive and Social Dentistry, School of Dentistry, Seoul National University, Seoul 03080, Korea
}

\begin{abstract}
Background: Erosion is a gradual process that occurs fairly quickly, and the full extent of the erosive effects of acidic beverages is not yet clear. The present study aimed to determine the differences in the erosive potentials among four naturally acidic fruit nectars within the same range of titratable acidity and to determine the influence of the components of organic acids on tooth erosion.

Methods: Diluted fruit nectars (mandarin 1:1.1, orange 1:1.7, lemon 1:15, grapefruit 1:20) with the same range of titratable acidity $(7.9 \mathrm{ml})$ and their corresponding organic acids $(0.05 \%, 0.1 \%, 0.3 \%$, and $0.5 \%$ citric acid, malic acid, and a citric and malic acid mixture [pH 2.8], respectively) were used. Specimens were placed in conical tubes with $50 \mathrm{ml}$ of each of the test solutions for 1 hour. A microhardness test and scanning electron microscopy were used to measure enamel erosion. Acid separation was carried out using high-performance liquid chromatography to analyze the composition of each test solution.

Results: Similar decreases in the Vickers hardness number (VHN) were observed among the groups treated with the following diluted fruit nectars: diluted mandarin nectar (75.9 $\Delta \mathrm{VHN}$ ), diluted lemon nectar (89.1 $\Delta \mathrm{VHN}$ ), diluted grapefruit nectar (91.7 $\Delta \mathrm{VHN}$ ), and diluted orange nectar (92.5 $\Delta \mathrm{VHN})$. No statistically significant differences were found in the enamel surface hardness after erosion $(p>0.05)$. Citric and malic acids were the major organic acids in the test fruits. The lemon and orange groups had the highest malic acid concentrations, and the mandarin group had the lowest malic acid concentration.

Conclusion: The titratable acidity and the citric and malic acid contents of the fruits could be crucial factors responsible for enamel erosion. Therefore, fruit-based drinks should be regarded as potentially erosive.
\end{abstract}

Key Words: Acids, Hardness, Microscopy, Tooth erosion

\section{Introduction}

In recent studies, tooth erosion has become increasingly recognized as a significant factor that plays a role in tooth loss among all age groups ${ }^{1-4)}$. Tooth erosion is defined as the loss of the hard dental structure due to chemical dissolution and not due to bacteria in the mouth ${ }^{5)}$. The complex and multifactorial etiology of tooth erosion is attributed to a wide range of extrinsic and intrinsic factors $^{6}$. Diet is thought to be the main extrinsic factor in the etiology of tooth erosion and has received the most attention in the dental literature ${ }^{7)}$. It is attributed to the excessive intake of acidic beverages, acidic fruits, and fruit juices $^{8)}$. The most frequently consumed erosive acids are phosphoric and fruit acids, which predominantly contain citric and malic acids ${ }^{9}$. The erosive activities of citric, malic, phosphoric, and other acids have been investigated and demonstrated in many in vitro, in situ, and in vivo studies ${ }^{9-12)}$.

Traditionally, researchers have believed that $\mathrm{pH}$ is an accurate indicator of the erosive potential of an acid ${ }^{13)}$. However, the $\mathrm{pH}$ is only an indicator of the number of hydrogen ions that are present in a solution and not of the presence of undissociated acid, whereas titratable acidity is a measure of the total acid content that allows solutions to resist $\mathrm{pH}$ change. Thus, measuring titratable acidity could be a more useful means for predicting the erosive potential of a food item ${ }^{14)}$, which is widely accepted as a 
crucial factor for measuring the extent of tooth erosion ${ }^{15-19)}$. Many children consume a large amount of diluted fruit drinks ${ }^{18,20,21)}$. This phenomenon has also been observed in Korea. Among other dietary changes, fruit importation and consumption have increased owing to free trade agreements with many countries, such as the USA, and internationalization. The increase in fruit juice consumption may be reflected by an increase in the cases of tooth erosion ${ }^{10)}$. These dietary changes have occurred relatively quickly, and the full extent of the erosive effects of acidic beverages is not yet clear ${ }^{18)}$.

Despite the increase in the consumption of fruits and fruit juices, tooth erosion has received little attention. Most studies have only measured the $\mathrm{pH}$ or titratable acidity corresponding to these fruits and their juices. However, few studies have applied the same level of titratable acidity to all their test samples. We hypothesized that if we applied the same titratable acidity level to all the acidic fruit nectars being tested, the factors that are potentially responsible for tooth erosion corresponding to their specific organic acid compositions could be examined and analyzed more precisely. Therefore, the present study aimed to confirm the differences in the erosive potentials among four naturally acidic fruit nectars within the same range of titratable acidity. Additionally, the influence of the components of their organic acids on tooth erosion was studied.

\section{Materials and Methods}

\section{Selection of products and preparation of the test solutions}

Four types of acidic fruits were selected for this study: oranges, which are a very common citrus fruit and the most popular fruit that Americans eat ${ }^{22)}$; lemons, which are the sourest fruit; grapefruit, which are becoming increasingly common; and mandarins, which are the most popular fruit consumed by Koreans. Further, distilled water was used as the control solution.

An electric juicer (Hurom, Gimhae, Korea) was used to prepare the fruit nectars. Each fruit nectar was centrifuged for 30 minutes at $8,000 \mathrm{rpm}$ using a high-speed centrifuge (RC-6 Plus; Thermo Electron Laboratory Equipment,
Waltham, MA, USA). After the centrifugation, the supernatant was collected, and the diluted fruit nectars were adjusted to the same titratable acidity level. The titratable acidity was measured using a $\mathrm{pH}$ electrode (Orion ROSS $^{\mathrm{TM}}$ 8102BNUWP; Thermo Fisher Scientific, Beverly, MA, USA) connected to a $\mathrm{pH}$ meter (Orion $\mathrm{Star}^{\mathrm{TM}}$; Thermo Fisher Scientific). The fruit nectar dilutions were prepared with distilled water as the diluent. Twenty millimeters of each of the diluted fruit nectars were placed in glass beakers, maintained at $37^{\circ} \mathrm{C}$, and were titrated by adding $7.9 \mathrm{ml}$ of $0.1 \mathrm{M}$ sodium hydroxide solution while measuring the $\mathrm{pH}$ until a $\mathrm{pH}$ of 5.5 was reached.

The $\mathrm{pH}$ of each experimental group, in which all the samples had the same titratable acidity, was measured with the methods proposed by Hunter et al. ${ }^{16)}$. Between measurements, the $\mathrm{pH}$ electrode was rinsed with distilled water. This process was performed in triplicate.

Concentrations of $0.05 \%, 0.1 \%, 0.3 \%$, and $0.5 \%$ corresponding to citric acid, malic acid, and a citric and malic acid mixture ( $\mathrm{pH} 2.8$ ), respectively, which are levels commonly found in fruit juice drinks ${ }^{23)}$, were used in these experiments.

\section{Specimen preparation}

Bovine enamel specimens were prepared using the method reported by a previous study ${ }^{17)}$. Small holes with a diameter of $5 \mathrm{~mm}$ were drilled on the top of the enamel surface. The samples were placed in molds measuring $1.2 \times 1.0 \times 0.8 \mathrm{~cm}$ with the labial surface embedded in acrylic resin. The specimens were polished and flattened with silicon carbide paper (600 to 2,000 grid) under cold water. All prepared specimens were stored at a constant relative humidity of $100 \%$ prior to use.

\section{Experimental procedure}

Two parameters were examined including the enamel erosion caused by the diluted fruit nectars and the organic acid concentration $\%(\mathrm{w} / \mathrm{v})$. A total of 48 specimens were randomly allocated to groups corresponding to each of the diluted fruit nectars and were placed in conical tubes with $50 \mathrm{ml}$ of the corresponding test solutions. The conical tubes were then placed in a thermostatically controlled agitator at $37^{\circ} \mathrm{C}$ with a speed of $150 \mathrm{rpm}$ and were stirred 
for 1 hour. After the exposure, the specimens were removed from the experimental solution and rinsed with distilled water. Sixty specimens were agitated in $0.05 \%$, $0.1 \%, 0.3 \%$, and $0.5 \%(\mathrm{w} / \mathrm{v})$ concentrations for 1 hour at $37^{\circ} \mathrm{C}$ at a speed of $150 \mathrm{rpm}$.

\section{Measurement of erosive potential}

The enamel microhardness of the specimens was determined using a Vickers microhardness tester (HMV-2; Shimadzu, Kyoto, Japan). Three indentations were measured for 10 seconds using a diamond at $9.81 \mathrm{~N}$ with $40 \times$ magnification lenses. Following this, the average microhardness was calculated.

All the specimens were sputter-coated with platinum and observed under a scanning electron microscope (SEM) (S-4700; HITACHI, Tokyo, Japan). The surfaces were photographed at a magnification of $\times 5,000$ and $15 \mathrm{kV}$ accelerating voltage.

\section{Liquid chromatographic analysis}

The separation of acids was performed using a high-performance liquid chromatograph (Ultimate 3000; Dionex, Sunnyvale, CA, USA) equipped with a $250 \mathrm{~mm} \times$ $4.6 \mathrm{~mm} \times 5 \mu \mathrm{m} \mathrm{C}-18$ column (Inno column; Innopia, Seongnam, Korea). The sample thermostat was maintained at $25^{\circ} \mathrm{C}$. The injected sample volume was $10 \mu \mathrm{l}$, and the mobile phase was a gradient of $\mathrm{A}\left(20 \mathrm{mM} \mathrm{KH}_{2} \mathrm{PO}_{4}\right)$ and $\mathrm{B}$ (acetonitrile): 0 to 15 minutes $100 \% \mathrm{~A}, 15$ to 20 minutes $100 \%$ B, 20 to 25 minutes $100 \%$ B, 25 to 26 minutes $100 \%$
$\mathrm{A}$, and 26 to 30 minutes $100 \% \mathrm{~A}$. The flow rate was 0.5 $\mathrm{ml} / \mathrm{min}$, and the detector was set at UV $215 \mathrm{~nm}$.

\section{Measurement of titratable acidity}

The titratable acidity levels of the organic acids (citric acid, malic acid, and a citric and malic acid mixture) were measured using $20 \mathrm{ml}$ samples of each the acids. Each acid was placed in an incubator at $37^{\circ} \mathrm{C}$. Following this, $0.1 \mathrm{M}$ sodium hydroxide solution was gradually pipetted until the $\mathrm{pH}$ reached 5.5, and the solution was stirred for 1 minute. The volume of sodium hydroxide was recorded. This process was repeated three times for each acid.

\section{Statistical analysis}

The data obtained on the microhardness were statistically analyzed by a one-way analysis of variance for the four experimental groups and a post-hoc Tukey's honest significant difference test using the Student's t-test range of values. The IBM SPSS statistical program ver 19.0 (IBM Co., Armonk, NY, USA) was used for the statistical analyses.

\section{Results}

Among the four groups corresponding to each of the diluted fruit juices, the diluted lemon nectar (1:15) had the lowest $\mathrm{pH}$ (2.74), the diluted mandarin nectar (1:1.1) had a $\mathrm{pH}$ of 3.58 , the diluted orange nectar (1:1.7) had a $\mathrm{pH}$ of 3.82 , and the diluted grapefruit nectar $(1: 20)$ had the

Table 1. Comparison of the Surface Microhardness and Surface Roughness Measurements of Different Groups before Treatment and after Erosion with Diluted Fruit Nectars

\begin{tabular}{|c|c|c|c|c|c|c|c|c|c|}
\hline \multirow{2}{*}{ Diluted fruit nectar } & \multirow{2}{*}{$\mathrm{n}$} & \multirow{2}{*}{$\mathrm{pH}$} & \multirow{2}{*}{$\begin{array}{c}\text { TA } \\
(\mathrm{ml})\end{array}$} & \multicolumn{2}{|c|}{ VHN } & \multirow{2}{*}{$\Delta \mathrm{VHN}$} & \multicolumn{2}{|c|}{ Surface roughness $(\mathrm{Ra})$} & \multirow{2}{*}{$\Delta \mathrm{Ra}$} \\
\hline & & & & Before & After & & Before & After & \\
\hline \multicolumn{10}{|l|}{ Experimental solutions } \\
\hline Mandarin:water (1:1.1) & 12 & 3.58 & 7.9 & $314.8 \pm 7.8$ & $238.9 \pm 15.2$ & $-75.9 \pm 14.7^{\mathrm{a}}$ & $0.69 \pm 0.12$ & $0.74 \pm 0.08$ & $0.05 \pm 0.34^{\mathrm{a}}$ \\
\hline Orange:water (1:1.7) & 12 & 3.82 & 7.9 & $308.1 \pm 14.7$ & $215.6 \pm 15.7$ & $-92.5 \pm 15.7^{\mathrm{a}}$ & $0.70 \pm 0.14$ & $1.05 \pm 0.17$ & $0.35 \pm 0.22^{\mathrm{b}}$ \\
\hline Lemon:water (1:15) & 12 & 2.74 & 7.9 & $313.2 \pm 12.7$ & $224.1 \pm 19.2$ & $-89.1 \pm 19.9^{\mathrm{a}}$ & $0.60 \pm 0.18$ & $0.94 \pm 0.13$ & $0.34 \pm 0.27^{\mathrm{b}}$ \\
\hline Grapefruit:water (1:20) & 12 & 4.02 & 7.9 & $314.6 \pm 10.9$ & $222.8 \pm 8.8$ & $-91.7 \pm 12.8^{\mathrm{a}}$ & $0.60 \pm 0.11$ & $0.75 \pm 0.07$ & $0.15 \pm 0.11^{b}$ \\
\hline \multicolumn{10}{|l|}{ Control solution } \\
\hline Artificial saliva & 12 & 7.00 & - & $309.6 \pm 5.9$ & $312.2 \pm 5.8$ & $2.6 \pm 2.3^{\mathrm{b}}$ & $0.55 \pm 0.09$ & $0.46 \pm 0.05$ & $-0.10 \pm 0.07^{\mathrm{c}}$ \\
\hline
\end{tabular}

Values are presented as number or mean \pm standard deviation.

TA: titratable acidity, VHN: Vickers hardness number.

a,b,c,d The different characters indicate statistically significant differences between groups according to a Tukey's honest significant difference post-hoc test at $\mathrm{p}<0.05$. 
highest $\mathrm{pH}$ (4.02).

The baseline microhardness was within a range of Vickers hardness numbers (VHN) of 308.1 to 314.8 VHN. Table 1 shows the mean enamel surface hardness after the exposure to the four different diluted fruit nectars. Similar decreases in the VHN were observed in the groups treated with each of the diluted fruit nectars: diluted mandarin nectar (75.9 $\Delta \mathrm{VHN})$, diluted lemon nectar (89.1 $\Delta \mathrm{VHN})$, diluted grapefruit nectar $(91.7 \Delta \mathrm{VHN})$, and diluted orange nectar (92.5 $\Delta \mathrm{VHN})$. Erosion occurred in all groups, but there were no statistically significant differences observed among the groups $(\mathrm{p}>0.05)$.

The SEM micrographs of the enamel specimens after being immersed in each of the test solutions are presented
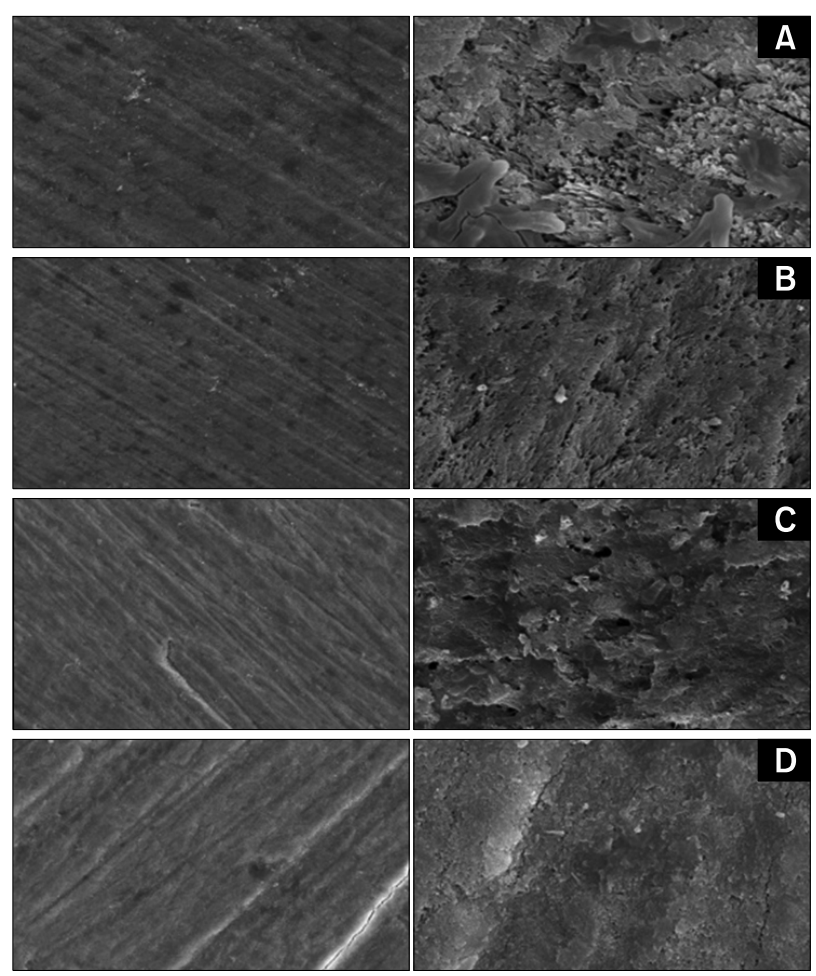

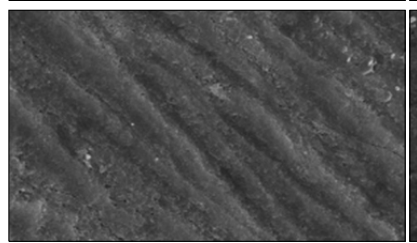

Before

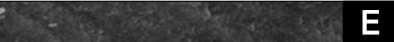

Fig. 1. Scanning electron micrographs of specimens that were placed in each test solution for 1 hour $(\times 5,000)$. (A) Diluted mandarin nectar group. (B) Diluted orange nectar group. (C) Diluted lemon nectar group. (D) Diluted grapefruit nectar group. (E) Artificial saliva (control). in Fig. 1. The SEM images of the specimens exposed to the diluted lemon nectar showed substantial demineralization, and their dentinal tubules were partially opened. The SEM images of the specimens treated with the diluted orange nectar showed an irregular surface demineralization and traces of opened dentinal tubules. The SEM images of the specimens exposed to the diluted grapefruit nectar showed different results compared to the specimens exposed to the lemon and orange nectars with some demineralization on the enamel surface. The SEM images of the specimens treated with the diluted mandarin nectar also differed from the specimens of the other groups (Fig. 1).

Different concentrations of organic acids were analyzed by mobile phases to obtain the optimal response and to separate the organic acids. Citric and malic acids were the major organic acids in all the test fruits. The lemon and orange groups had the highest malic acid concentrations. The mandarin group had the lowest malic acid concentration (Fig. 2).

Among the organic acids, malic acid tended to have the highest titratable acidity. As the acid concentration increased, the titratable acidity level tended to increase. It is interesting to note that malic acid produced higher titratable acidity than citric acid as well as a citric and malic acid mixture. Citric acid and the citric and malic acid mixture demonstrated no differences in titratable acidity (Table 2).
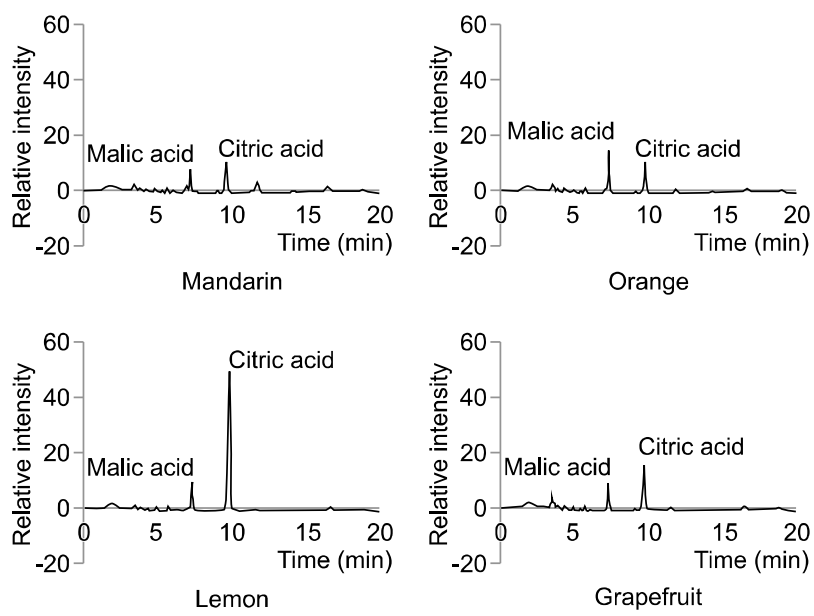

Fig. 2. Analysis of the high-performance liquid chromatograms obtained for the mandarin, lemon, orange, and grapefruit nectars. 
Table 2. Mean Titratable Acidity in the Organic Acids

\begin{tabular}{lr}
\hline \multicolumn{1}{c}{ Acid } & Titratable acidity $^{\mathrm{a}}$ \\
\hline Citric acid (\%) & \\
0.05 & $1.1 \pm 0.31$ \\
0.1 & $1.9 \pm 0.12$ \\
0.3 & $6.9 \pm 0.25$ \\
0.5 & $11.2 \pm 0.31$ \\
Malic acid (\%) & \\
0.05 & $1.4 \pm 0.15$ \\
0.1 & $2.6 \pm 0.26$ \\
0.3 & $7.3 \pm 0.32$ \\
0.5 & $13.0 \pm 0.17$ \\
Citric + malic acid $(\%)$ & \\
0.05 & $1.3 \pm 0.28$ \\
0.1 & $2.2 \pm 0.14$ \\
0.3 & $6.9 \pm 0.12$ \\
0.5 & $11.1 \pm 0.11$ \\
\hline
\end{tabular}

Values are presented as mean \pm standard deviation. ${ }^{\mathrm{a}}$ Millimeter of $0.1 \mathrm{M} \mathrm{NaOH}$.

\section{Discussion}

The prevalence of tooth erosion has increased over the past several decades ${ }^{1)}$ and has been a significant focus of dental research ${ }^{24)}$. Dietary erosion has been ascribed to an excessive intake of acidic beverages, acidic fruits, and fruit juices ${ }^{8)}$. Most of the previous studies ${ }^{10-13)}$ and the author's previous study ${ }^{17)}$ have evaluated the level of erosion by measuring the acidity or titratable acidity of a beverage, but this study is meaningful in that it evaluates the level of erosion by setting the titratable acidity of all the test solutions to the same level. The current study was designed to determine how diluted fruit nectars with the same titratable acidity affected the tooth structures and to analyze the influence of different organic acids on tooth erosion.

Enamel erosion occurred in all of the diluted fruit nectar groups. The results indicated that all the test solutions were highly acidic, even after they were diluted. These data were consistent with the results from a recent report by Cairns et al. ${ }^{19)}$, who also found that even a diluted test solution was highly acidic.

The depths of the lesions corresponding to the enamel erosion, which were measured using a microhardness tester after the treatment with the test solutions, were numerically similar. No significant differences were observed in enamel hardness among the specimens after erosion. There are no other factors that influence tooth erosion except for titratable acidity. The findings of this study differ from the results of Johansson et al. ${ }^{25)}$. However, titratable acidity has been proven to be a better indicator to evaluate the erosive potential of a beverage because it measures the actual amount of $\mathrm{H}^{+}$ions that can interact with the tooth surface ${ }^{7)}$. It has been generally demonstrated that titratable acidity is a better indicator of erosive potential than the $\mathrm{pH}$ alone $\mathrm{e}^{26,27)}$. The results of the present study correspond well with results from an earlier study that reported that enamel erosion increased with the increased consumption of high acid content foods and beverages $^{28-30)}$. This conclusion was also reached in the study by Cairns et al. ${ }^{19)}$. These previous studies used different experimental conditions than those of the present study, but all of the studies found that titratable acidity played a crucial role in enamel erosion.

The SEM analysis demonstrated the progressive destruction of the enamel ultrastructure, especially pertaining to the specimens immersed in the diluted lemon and orange nectars. The specimens exposed to the diluted orange nectar showed irregular demineralization of the enamel surface, and these data are consistent with the results from a recent report by Torres et al. ${ }^{30)}$, who found that exposure to a soy-based orange juice resulted in an irregular enamel surface after 60 days of immersion. In this study, the specimens from each of the groups showed different patterns on their enamel surfaces. The reason for this disparity is not apparent but may be related to the types of organic acids and mineral ion concentrations in the different fruit nectars. The chemical dissolution of teeth occurs via the hydrogen ions derived from the acids $^{31)}$. These ions can attack the tooth mineral crystals and can combine with carbonate or phosphate ions to dissolve the crystals by releasing all of the ions from the area of the crystal surface that was exposed to the acid, causing direct surface etching. Acids, such as citric acid, are double-acting and highly damaging to the tooth surface $^{32)}$. Grobler et al. ${ }^{33)}$ showed that the type of acid and its concentration are important factors that need to be considered in order to determine the amount of damage, even when the $\mathrm{pH}$ values among the acids are similar. 
Similar to previous studies, this phenomenon may lead to the assumption that each organic acid has its own dissolving characteristics.

In the present study, the organic acids were investigated independently. Citric and malic acids were the major organic acids in the test groups. The results of this study coincided well with results from an earlier study that reported that the acid comprising the highest proportion in both orange juice and lemon juice was citric acid, followed by malic acid ${ }^{34)}$. Citric acid, a complex organic acid with three acid dissociation constants, has an unusually high erosive potential in terms of its acidity and chelating properties, even if it is diluted. A higher content of citric acid in a food or beverage indicates significant erosive potential $^{16)}$.

Furthermore, malic acid was found in low concentrations in the mandarin solution and high concentrations in the orange and lemon solutions. This result was very similar to that of a previous study that demonstrated that malic acid was more erosive than citric acid and that malic and citric acids did not differ in their erosive potential ${ }^{35)}$. Malic acid showed the highest titratable acidity, and this phenomenon may lead to the assumption that malic acid may also affect the enamel. Based on this result, the need arises to discover the effects of the erosive potential of malic acid and to investigate how malic acid affects the enamel surface compared to citric acid by a further study. Compared to the organic acid compositions of diluted fruit nectars, approximately $0.3 \%$ of a citric and malic acid mixture was assumed to be in orange, lemon, and grapefruit nectars.

A limitation of this study stemmed from the fact that it was an in vitro study. Due to this, it was impossible to recreate an oral environment perfectly. Further, we only experimented with citrus fruit nectars. Therefore, we could not compare the differences among the many different types of fruits. Besides, this study used bovine enamel instead of human enamel, which may have affected the results. In a further study, the effects of the fruit nectars on human enamel need to be evaluated. Despite these limitations, this study is meaningful in that the experiment was carried out by setting the same titratable acidity level in all the test solutions, which was not performed in previous studies.

The titratable acidity corresponding to different types of fruits and their citric and malic acid contents could be crucial factors responsible for enamel erosion. Therefore, fruit-based drinks should be regarded as potentially erosive. Consumers should be aware of this potential danger, and public policies should provide preventive advice for the safe consumption of such beverages.

\section{Notes}

\section{Conflict of interest}

No potential conflict of interest relevant to this article was reported.

\section{Ethical approval}

Not applicable.

\section{ORCID}

Eun-Jeong Kim, https://orcid.org/0000-0002-6316-7807

Bo-Hyoung Jin, https://orcid.org/0000-0003-3526-6805

\section{Acknowledgements}

This paper was based on the thesis submitted by EJ Kim for a master's degree program, Seoul National University, Seoul, Korea, 2013.

\section{References}

1. Nunn JH, Gordon PH, Morris AJ, Pine CM, Walker A: Dental erosion-changing prevalence? A review of British national childrens' surveys. Int J Paediatr Dent 13: 98-105, 2003. https://doi.org/10.1046/j.1365-263X.2003.00433.x

2. Dugmore CR, Rock WP: The prevalence of tooth erosion in 12-year-old children. Br Dent J 196: 279-282; discussion 273, 2004. https://doi.org/10.1038/sj.bdj.4811040

3. Jaeggi T, Lussi A: Prevalence, incidence and distribution of erosion. In: Lussi A, ed. Dental erosion: from diagnosis to therapy. Karger, Basel, pp.44-65, 2006.

4. Harding MA, Whelton H, O'Mullane DM, Cronin M: Dental erosion in 5-year-old Irish school children and associated factors: a pilot study. Community Dent Health 20: 165-170, 2003. 
5. Imfeld T: Dental erosion. Definition, classification and links. Eur J Oral Sci 104: 151-155, 1996. https://doi.org/10.1111/j.1600-0722.1996.tb00063.x

6. Nunn JH: Prevalence of dental erosion and the implications for oral health. Eur J Oral Sci 104: 156-161, 1996. https://doi.org/10.1111/j.1600-0722.1996.tb00064.x

7. Zero DT: Etiology of dental erosion--extrinsic factors. Eur J Oral Sci 104: 162-177, 1996. https://doi.org/10.1111/j.1600-0722.1996.tb00065.x

8. Attin T, Meyer K, Hellwig E, Buchalla W, Lennon AM: Effect of mineral supplements to citric acid on enamel erosion. Arch Oral Biol 48: 753-759, 2003. https://doi.org/10.1016/S0003-9969(03)00156-0

9. Asher C, Read MJ: Early enamel erosion in children associated with the excessive consumption of citric acid. Br Dent J 162: 384-387, 1987. https://doi.org/10.1038/sj.bdj.4806141

10. Levine RS: Fruit juice erosion--an increasing danger? J Dent 2: 85-88, 1973. https://doi.org/10.1016/S0300-5712(73)80025-9

11. Fuller JL, Johnson WW: Citric acid consumption and the human dentition. J Am Dent Assoc 95: 80-84, 1977. https://doi.org/10.14219/jada.archive.1977.0551

12. Oh HN, Lee HJ: The effect of energy drink on enamel erosion. J Dent Hyg Sci 15: 419-423, 2015. https://doi.org/10.17135/jdhs.2015.15.4.419

13. Meurman JH, ten Cate JM: Pathogenesis and modifying factors of dental erosion. Eur J Oral Sci 104: 199-206, 1996. https://doi.org/10.1111/j.1600-0722.1996.tb00068.x

14. Grobler SR, van der Horst G: Biochemical analysis of various cool drinks with regard to enamel erosion, de- and remineralization. J Dent Assoc S Afr 37: 681-684, 1982.

15. Brown CJ, Smith G, Shaw L, Parry J, Smith AJ: The erosive potential of flavoured sparkling water drinks. Int J Paediatr Dent 17: 86-91, 2007. https://doi.org/10.1111/j.1365-263X.2006.00784.X

16. Hunter ML, Patel R, Loyn T, Morgan MZ, Fairchild R, Rees JS: The effect of dilution on the in vitro erosive potential of a range of dilutable fruit drinks. Int J Paediatr Dent 18: 251-255, 2008. https://doi.org/10.1111/j.1365-263X.2008.00917.x

17. Kim EJ, Lee HJ, Lee EJ, Bae KH, Jin BH, Paik DI: Effects of $\mathrm{pH}$ and titratable acidity on the erosive potential of acidic drinks. J Korean Acad Oral Health 36: 13-19, 2012.
18. Ehlen LA, Marshall TA, Qian F, Wefel JS, Warren JJ: Acidic beverages increase the risk of in vitro tooth erosion. Nutr Res 28: 299-303, 2008.

https://doi.org/10.1016/j.nutres.2008.03.001

19. Cairns AM, Watson M, Creanor SL, Foye RH: The $\mathrm{pH}$ and titratable acidity of a range of diluting drinks and their potential effect on dental erosion. J Dent 30: 313-317, 2002. https://doi.org/10.1016/S0300-5712(02)00044-1

20. Hourihane JO, Rolles CJ: Morbidity from excessive intake of high energy fluids: the 'squash drinking syndrome'. Arch Dis Child 72: 141-143, 1995. https://doi.org/10.1136/adc.72.2.141

21. Chu CH, Pang KK, Lo EC: Dietary behavior and knowledge of dental erosion among Chinese adults. BMC Oral Health 10: 13, 2010. https://doi.org/10.1186/1472-6831-10-13

22. Pollack SL, Lin BH, Allshouse J: Characteristics of U.S. orange consumption. United States Department of Agriculture, Washington, D.C., 2003. 17 p.

23. West NX, Hughes JA, Addy M: Erosion of dentine and enamel in vitro by dietary acids: the effect of temperature, acid character, concentration and exposure time. J Oral Rehabil 27: 875-880, 2000. https://doi.org/10.1111/j.1365-2842.2000.00583.x

24. Thylstrup A, Fejerskov O: Textbook of clinical cariology: caries chemistry and fluoride-mechanisms of action, diet and the caries process. 2nd ed. Munksgaard, Copenhagen, pp.231-257, 1994.

25. Johansson AK, Lingström $P$, Imfeld $T$, Birkhed D: Influence of drinking method on tooth-surface $\mathrm{pH}$ in relation to dental erosion. Eur J Oral Sci 112: 484-489, 2004. https://doi.org/10.1111/j.1600-0722.2004.00172.x

26. Grobler SR, Jenkins GN, Kotze D: The effects of the composition and method of drinking of soft drinks on plaque pH. Br Dent J 158: 293-296, 1985. https://doi.org/10.1038/sj.bdj.4805591

27. Edwards M, Creanor SL, Foye RH, Gilmour WH: Buffering capacities of soft drinks: the potential influence on dental erosion. J Oral Rehabil 26: 923-927, 1999. https://doi.org/10.1046/j.1365-2842.1999.00494.x

28. Park JH: A comparison study on the effects of commercial drinks on bovine enamel. J Dent Hyg Sci 9: 557-561, 2009.

29. Jun MK, Lee DH, Lee SM: Assessment of nutrient and sugar content and $\mathrm{pH}$ of some commercial beverages. J Dent Hyg Sci 16: 464-471, 2016. 
https://doi.org/10.17135/jdhs.2016.16.6.464

30. Torres CP, Chinelatti MA, Gomes-Silva JM, et al: Surface and subsurface erosion of primary enamel by acid beverages over time. Braz Dent J 21: 337-345, 2010. https://doi.org/10.1590/S0103-64402010000400009

31. Fejerskov O, Kidd EAM: Dental caries. The disease and its clinical management. In: ten Cate JM, Larsen MJ, Pearce EIF, Fejerskov O, eds. Chemical interactions between the tooth and oral fluids. Blackwell, Oxford, pp.50-51, 2004.

32. Featherstone JD, Lussi A: Understanding the chemistry of dental erosion. Monogr Oral Sci 20: 66-76, 2006.

https://doi.org/10.1159/000093351
33. Grobler SR, Senekal PJ, Laubscher JA: In vitro demineralization of enamel by orange juice, apple juice, Pepsi Cola and Diet Pepsi Cola. Clin Prev Dent 12: 5-9, 1990.

34. Flores P, Hellín P, Fenoll J: Determination of organic acids in fruits and vegetables by liquid chromatography with tandem-mass spectrometry. Food Chem 132: 1049-1054, 2012. https://doi.org/10.1016/j.foodchem.2011.10.064

35. Hughes JA, West NX, Parker DM, van den Braak MH, Addy $\mathrm{M}$ : Effects of $\mathrm{pH}$ and concentration of citric, malic and lactic acids on enamel, in vitro. J Dent 28: 147-152, 2000.

https://doi.org/10.1016/S0300-5712(99)00060-3 